\title{
New aspects about the search for the most relevant parameters for optimization of SLM materials
}

\author{
Tatiana Mishurova ${ }^{1}$, Katia Artzt ${ }^{2}$, Jan Haubrich ${ }^{2}$, Guillermo Requena ${ }^{2}$, and Giovanni \\ Bruno ${ }^{1,3, *}$ \\ ${ }^{1}$ Bundesanstalt für Materialforschung und-prüfung (BAM; Federal Institute for Materials \\ Research and Testing), Unter den Eichen 87, Berlin 12205, Germany; \\ tatiana.mishurova@bam.de \\ 2 Institute of Materials Research, German Aerospace Center (DLR; Deutsches Zentrum für \\ Luft-und Raumfahrt), Linder Höhe, Cologne 51147, Germany; katia.artzt@dlr.de; \\ jan.haubrich@dlr.de; guillermo.requena@dlr.de \\ ${ }^{3}$ Institute of Physics and Astronomy, University of Potsdam, Karl-Liebknecht-Straße 24/25, \\ Potsdam 14476, Germany \\ * Correspondence: giovanni.bruno@bam.de; Tel.: +49-30-81041850
}

\begin{abstract}
While the volumetric energy density is commonly used to qualify a process parameter set, and to quantify its influence on the microstructure and performance of additively manufactured (AM) materials and components, it has been already shown that this description is by no means exhaustive. In this work, new aspects of the optimization of the selective laser melting process are investigated for AM Ti-6Al-4V. We focus on the amount of near-surface residual stress (RS), often blamed for the failure of components, and on the porosity characteristics (amount and spatial distribution). First, using synchrotron $\mathrm{x}$-ray diffraction we show that higher RS in the subsurface region is generated if a lower energy density is used. However, we show that laser de-focusing and sample positioning inside the build chamber also play an eminent role, and we quantify this influence. In parallel, using X-ray Computed Tomography, we observe that porosity is mainly concentrated in the contour region, except in the case where the laser speed is small. The low values of porosity (less than 1\%) do not influence RS.
\end{abstract}

Keywords: SLM, Ti-6Al-4V, X-ray synchrotron diffraction, computed tomography, residual stress 


\section{Introduction}

One of the key strengths of selective laser melting (SLM) is the fabrication of near net-shape, economically attractive metallic components with complex geometries, not otherwise achievable with conventional production methods [1]. For instance, 50\% reduction of the production costs has been reported for a conventionally fabricated wrought Ti-6Al-4V engine bracket using AM technology [2].

Material density, or conversely porosity, is one of the first characteristics that are investigated in the search for an optimal SLM processing windows. Varying scanning speed and laser power, for example, changes the dimensions of melt pools, leading to the generation of different kinds of defects such as spheroidal keyhole pores and crack-like voids, due to lack of fusion [3, 4]. Particularly crack-like voids, which in SLM are oriented roughly parallel to consolidated layers, can significantly reduce the lifetime of components under fatigue load [5]. A porosity estimation by using the Archimedes method or 2D microscopy characterization does not give full information about critical defects such as the spatial distribution of all voids and their three-dimensional morphology [6]. Therefore, X-ray computed tomography (CT) is commonly used for 3D porosity analysis in AM parts [7], allowing mapping voids down to the achievable resolution of the instrument. In fact, 3D microstructure characterization is necessary to determine the shape of pores. Since pore size distribution and pore shapes in SLM are highly influenced by the energy input as well as the scanning strategy $[7,8]$, CT can be an ideal analysis tool to determine process windows in terms of material density.

The optimization of the SLM process can be performed by various strategies. Since the analysis of all parameter sets that influence AM parts is a complex matter, i.e. a multitude of parameters such as laser power $(P)$, scanning velocity $(v)$, hatch distance $(h)$, or powder layer thickness $(x)$ must be considered, the volumetric energy density $\left(E_{\mathrm{v}}\right)$ is often applied as a simple approximation:

$$
E_{\mathrm{v}}=\frac{P}{v \cdot h \cdot x}
$$

However, one has to bear in mind that $E_{V}$ convolutes the parameters and represents a significant simplification, i.e. similar $E_{V}$ can result for different combinations of scanning parameters, leading to very different material properties. While generally very useful for comparison purposes, $E_{V}$ should be used with caution. For instance, Prashanth et al. [9] have reported a sizeable change in porosity despite constant $E_{V}$. Additionally, $E_{V}$ cannot quantify 
melt pool characteristics, because the track width and height of the solidified melt pool have shown to be different at constant $E_{V}[10]$.

For the particular case of Ti-6Al-4V, currently the most relevant $\mathrm{Ti}$ alloy produced by SLM, the parameters involved in $E_{V}$ can be tuned to obtain partially stabilized lamellar $\alpha+\beta$ microstructures, exhibiting a good ductility [11-13], or $\alpha / \alpha^{\prime}$ martensite, possessing a high density of lattice defects and showing brittle behavior [14]. The origin of these differences lies in the thermal history during SLM, usually termed intrinsic heat treatment (IHT) $[12,13,15]$. To a certain degree, this IHT can be intensified by choosing certain process parameters (e.g. low hatch distance or low velocities), which gives the possibility to tailor and stabilize the microstructure operando during processing [13].

The presence of residual stress (RS) after production can have a high impact on the chosen build strategy as well as on the mechanical performance of final components [16]. RS can be critical for components, since it can introduce geometrical distortion and cracking of the parts even during production [17] as well as detachment from the build platform. The latter is equivalent to a build job failure.

Several studies of RS by destructive techniques (e.g. by the contour method [4], hole drilling [18], or the bridge curvature method (BCM)[19]) have been reported. However, the use of destructive techniques limits further investigation of samples. The most common nondestructive technique for the determination of RS is laboratory X-ray diffraction (XRD), which allows analysing materials to a shallow depth (around $5 \mu \mathrm{m}$ for Ti-6Al-4V). This, however, is often insufficient, due to the high as-built surface roughness of SLM parts [20]. Synchrotron X-ray diffraction (SXRD) allows overcoming this limit and accessing subsurface $\mathrm{RS}$ in a spatially resolved manner. With a white X-ray beam, for instance, it is possible to obtain the residual stress profiles as function of the depth from the surface in one single measurement [21, 22].

It has been shown experimentally [21, 23-25] and by modelling [26] that SLM parts present a surface tensile RS state in as-built condition. Such stresses play a critical role during fatigue, since they can promote faster crack propagation from the surface. Using the BCM approach, other authors have optimized the SLM processing conditions with respect to RS by varying different production parameters (i.e., laser velocity, scanning strategy) [19]. The BCM has also been validated by SXRD [21], where a correlation was found between higher RS and lower energy density $\left(E_{V}\right)$.

Building on our previous works, showing possible ways of optimizing SLM processing parameters by means of bulk porosity fractions [4], and identifying synchrotron radiation as 
the ideal tool to determine residual stresses [27], in the present study we show the importance of subsurface RS (in the as-built state) to derive guidelines for a more systematic SLM process adjustment.

\section{Experimental}

\subsection{Materials}

Prisms $\left(5 \times 5 \times 15 \mathrm{~mm}^{3}\right)$ were produced in a SLM Solutions $280 \mathrm{HL}$ machine using plasma atomized Ti-6Al-4V ELI grade 23 powder from AP\&C, with a particle size of $\mathrm{d}_{90}<50 \mu \mathrm{m}$. The specimens were built directly on a baseplate preheated to $200{ }^{\circ} \mathrm{C}$, without need for support structures. A powder layer thickness of $30 \mu \mathrm{m}$ and a chess-pattern scan strategy with a minimum field size of $5 \mathrm{~mm}$ were chosen (a fresh powder batch was used, ensuring no oxygen contamination). For all samples, a set of two contours and one intermediate line (i.e., fill-contour line) were applied before the sample bulk was processed. Special contour parameters were used: laser power of $100 \mathrm{~W}$ and scan velocity of $525 \mathrm{~mm} / \mathrm{s}$. The scanning and recoating time per layer (overall called "layer time") amounted to around $19 \mathrm{~s}$ in total.

Table 1. Manufacturing parameters of the investigated samples.

\begin{tabular}{|c|c|c|c|c|c|c|}
\hline Name & $\begin{array}{c}\text { Power } \\
\text { p }\end{array}$ & $\begin{array}{c}\text { Hatch } \\
\text { distance } \\
\mathbf{h}\end{array}$ & $\begin{array}{c}\text { Velocity } \\
\text { v }\end{array}$ & $\begin{array}{c}\text { Focus } \\
\mathbf{f}\end{array}$ & $\begin{array}{c}\text { Energy } \\
\text { Density } \\
\mathbf{E}_{\mathbf{V}}\end{array}$ & $\begin{array}{c}\text { Line } \\
\text { energy } \\
\mathbf{P} / \mathbf{v}\end{array}$ \\
\hline & $\mathrm{W}$ & $\mathrm{mm}$ & $\mathrm{mm} / \mathrm{s}$ & $\mathrm{mm}$ & $\mathrm{J} / \mathrm{mm}^{3}$ & $\mathrm{~J} / \mathrm{mm}$ \\
\hline A4 & 175 & 0.1 & 500 & 0 & 117 & 0.35 \\
\hline A4VP70 & 70 & 0.1 & 200 & 0 & 117 & 0.35 \\
\hline A4VP280 & 280 & 0.1 & 800 & 0 & 117 & 0.35 \\
\hline A4F-2 & 175 & 0.1 & 500 & -2 & 117 & 0.35 \\
\hline$A 4 F+2$ & 175 & 0.1 & 500 & 2 & 117 & 0.35 \\
\hline A1 & 175 & 0.1 & 200 & 0 & 292 & 0.88 \\
\hline A1H40 & 175 & 0.04 & 500 & 0 & 292 & 0.35 \\
\hline
\end{tabular}

Different SLM bulk process parameters were chosen (Table 1): the parameter set A4 corresponds to the optimum material density previously determined (using the same SLM machine) and reported in [4, 28]. Around this optimum, the laser power and the scan velocity were varied keeping the volume energy density $E_{V}$ constant. Moreover, the effects of laser focus position were studied in a limited interval, although this parameter is not included in the definition of $E_{V}$ (equation 1). Negative focus values indicate that the laser focus is $2 \mathrm{~mm}$ above the powder bed. In addition, two particular parameter sets, leading to very high energy 
input into the material (IHT parameters A1 and the derived A1H40), have been considered, since our previous studies showed low RS [21], a stable $\alpha+\beta$ microstructure, and a reduced texture at acceptable porosity [13]. Short layer scan times have been ensured to render intensified IHT effective. Finally, the effect of location of samples at different positions on the base plate for condition A4 was also investigated at constant SLM process parameters.

\subsection{Residual stress determination}

The residual stress analysis was carried out at the synchrotron source BESSY II (Helmholtz Zentrum Berlin, Germany) at the EDDI beamline [22]. This beamline provides a white beam with an energy range of about 10 to $150 \mathrm{keV}$. The experiment was performed in a reflection set-up with a fixed diffraction angle of $2 \theta=8^{\circ}$ (Fig.1a). The prismatic gauge volume was defined by the intersection of the incoming and the diffracted beams towards the detector. Primary slits with an opening of $500 \times 500 \mu \mathrm{m}^{2}$, and secondary slits with a vertical opening of $30 \mu \mathrm{m}$ were used, yielding a gauge volume length of $3.8 \mathrm{~mm}$. The gauge volume length almost covered the whole prism base size, so that the stress component along $\mathrm{Y}$ was nearly averaged to zero. While this component could be very interesting, its determination is left for future work. We focused our attention on the determination of the stress component in the building direction (along $\mathrm{Z}$ axis, Fig.1b), since it would allow relevant comparison among samples. For each measurement point, a $\sin ^{2} \psi$ scan (see [27]) was performed with $10 \psi$-tilts. The coordinate system used on the prismatic specimen during data analysis, and the measurement points with schematic gauge volumes are depicted in Fig. 1b. For all samples the measurements were performed at the surface facing the same direction during production. The normal surface stress component $\left(\psi=0^{\circ}\right.$, Fig. 1a) was assumed to be negligible in the case of the reflection geometry. Therefore, using the $\sin ^{2} \psi$ method [29] the values of RS in the

building direction could be obtained from the linear regression of $d_{\varphi \psi}^{h k l} v s . \sin ^{2} \psi$ graphs. Diffraction peaks of six crystallographic planes of $(\alpha+\alpha)$ hexagonal Ti lattices could be observed. For the calculation of strains and stresses, diffraction elastic constants (DEC, reported in [21]) of $\alpha$-Ti were calculated using the Eshelby/Kröner model [30, 31]. The crystallographic plane $\{103\}$ of $\left(\alpha+\alpha^{\prime}\right)$ Ti was chosen for data representation, due to its low intergranular stress $[32,33]$. Under such experimental conditions, the penetration depth of Xrays was about $120 \mu \mathrm{m}$ for the 103 reflection. Since the surface roughness (waviness due to the AM process) was less than $10 \mu \mathrm{m}, \mathrm{RS}$ analysis could be considered truly sub-surface. It is worth mentioning that while the $\beta$-phase was visible in the some of the diffraction patterns, it was not present in all samples and not observable at all $\psi$ tilts. Although already done in the 
literature [34], a reliable determination of the stress in the $\beta$-phase (and above all a comparison among all samples) was not possible in the present study.

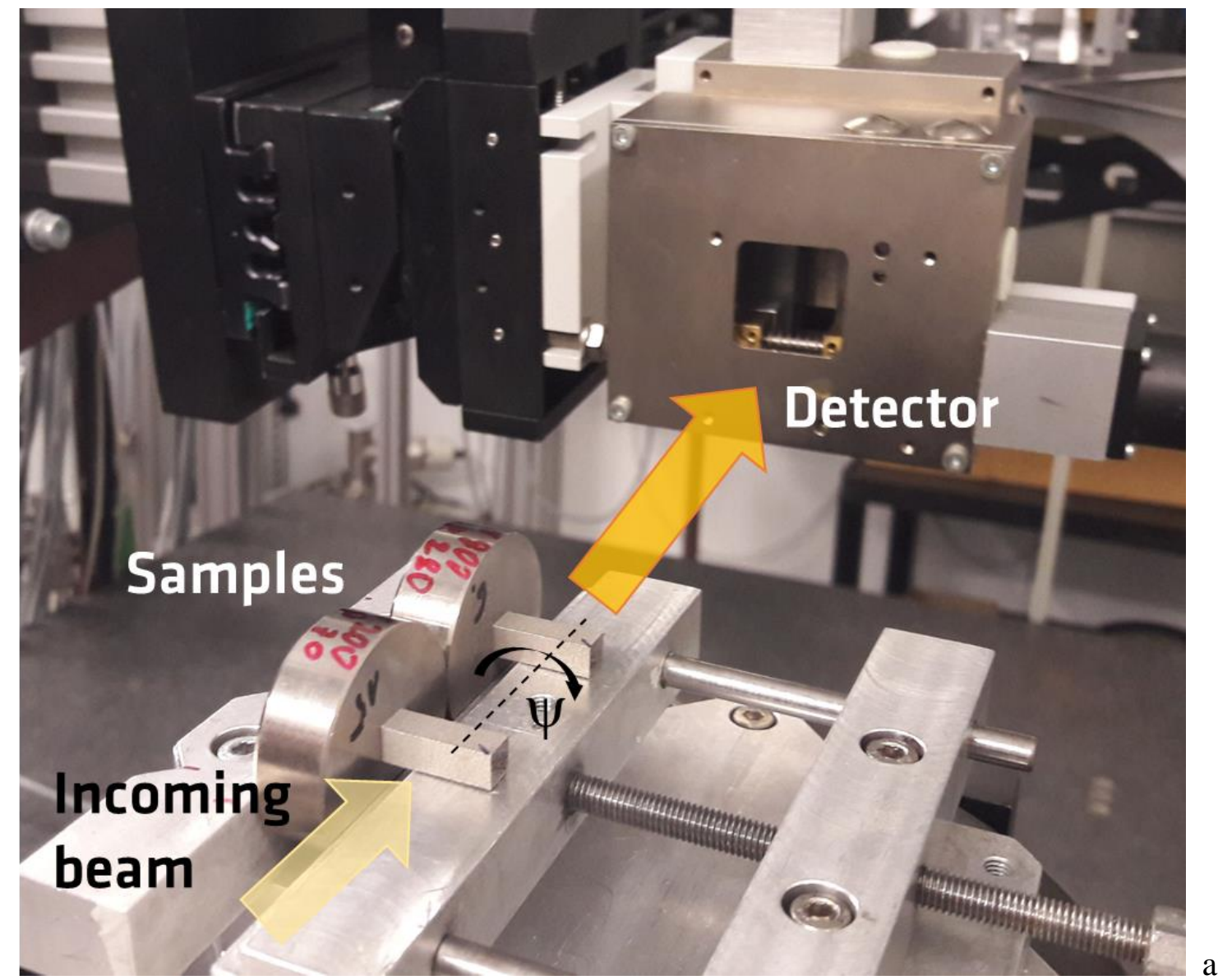

a)

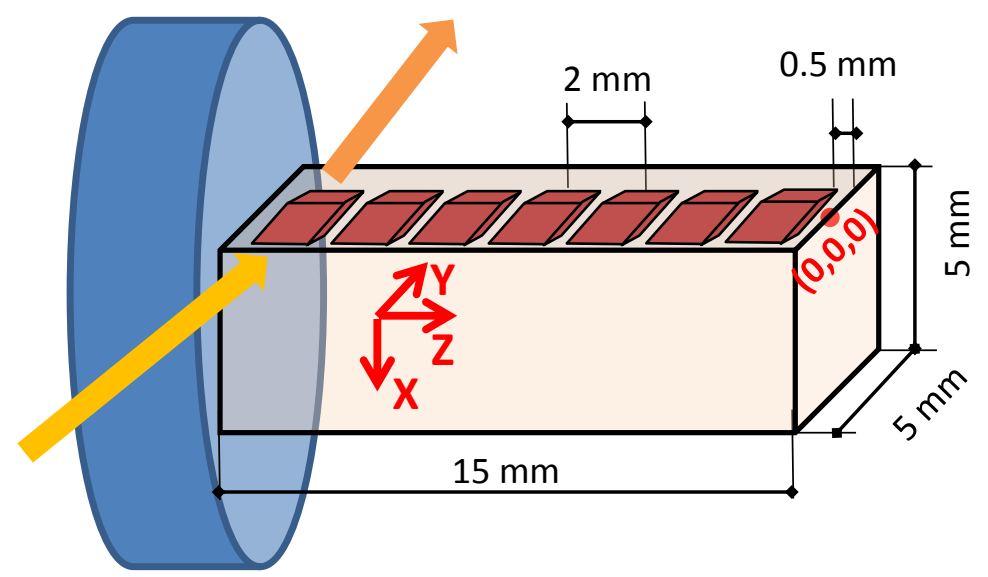

b)

Fig. 1. a) Set-up on EDDI beamline (at $\psi=0^{\circ}$ ), with the outgoing beam slits in the back (the beam axis is parallel to the clamps); Samples were tilted around an axis being the intersection of the sample surface and diffraction plane. b) A prismatic sample with schematic representation of the measured points and gauge volumes. Note that the sketch of the gauge 
volume in b) has been exaggerated for clarity, and is not to scale (actual size is $500 \times 500 \times$ $\left.30 \mu \mathrm{m}^{3}\right)$.

\subsection{X-ray Computed tomography}

CT of the cuboids was performed by using a v|tome|x L 300 CT scanner from General Electric, in particular to determine porosity characteristics. 2300 projections were acquired during each scan. A tube voltage of $170 \mathrm{keV}$ and a current of $55 \mu \mathrm{A}$ were used, and the acquisition time for each projection was $2 \mathrm{~s}$. A voxel size of $(7.1 \mu \mathrm{m})^{3}$ was achieved. A 0.25 $\mathrm{mm} \mathrm{Cu}$ filter was used to reduce the influence of low-energy X-rays. Data processing was performed by using the AvizoFire 9.4 software package. Only voids with a minimum size of 10 voxels were considered, to reduce the probability of false segmentation due to image artifacts. In order to account for an error in segmentation, three different threshold values were taken, and the standard deviation among the determined volume fractions was calculated. This allowed detecting pores down to $(15.3 \mu \mathrm{m})^{3}$, thus providing an accurate lower limit of total porosity $[4,28]$. Sphericity of pores $\Psi$ was calculated as

$$
\Psi=\frac{6 \cdot \pi^{\frac{1}{2}} \cdot V}{A^{\frac{3}{2}}}
$$

where $V$ is the volume and $A$ is the surface area of a pore.

\subsection{Electron Microscopy}

For microstructure investigations, all specimens were ground and then polished with an aqueous suspension of $0.04 \mu \mathrm{m} \mathrm{SiO} \mathrm{S}_{2}$ particles with the addition of $10 \% \mathrm{H}_{2} \mathrm{O}_{2}$. Scanning electron microscopy (SEM) was conducted using the backscattered electron mode (BSE) of a FEI Helios Nanolab 600i dual beam microscope with a CBS detector (3 kV operation voltage, $\sim 80 \mathrm{pA}, \sim 5 \mathrm{~mm}$ working distance).

\section{Results}

\subsection{Microstructure as a function of process parameter sets}

The evolution of synchrotron XRD diffractograms as a function of the sample height $\mathrm{Z}$ is shown in Fig. 3 for the A1H40 $\left(E_{v}=292 \mathrm{~J} / \mathrm{mm}^{3}\right.$; IHT $)$ and A4 $\left(E_{v}=117 \mathrm{~J} / \mathrm{mm}^{3}\right.$; optimized $)$ conditions.

The intensified IHT in A1H40 leads to the formation of $\beta$ phase at the interface of $\alpha$ lamellae (see SEM picture in Fig.3b). The $\beta-110$ peak can be seen along the whole height of the 
sample. This is in good agreement with previous investigations [13], where only the very top layers $(Z \sim 0.2 \mathrm{~mm})$, not reheated by successive passes, show martensitic $\alpha+\alpha$. On the other hand, no $\beta$ phase forms in $\mathrm{A} 4$, manufactured with lower $E_{V}$, (Fig. $3 \mathrm{c}$ and d). Moreover, a microstructure change can be observed from the central region to near the top of the sample $(\mathrm{Z}=2.5 \mathrm{~mm})$ in the case of manufacturing conditions with different focus position $(\mathrm{A} 4 \mathrm{~F}+2$ and A4F-2), (Fig. 4): diffractograms at some $\psi$ angles show the presence of $\beta-110$ peak, and the $\beta$ phase can be observed in the SEM image for A4F-2 (Fig. 4b, red oval). This effect is less pronounced in the XRD analysis of $\mathrm{A} 4 \mathrm{~F}+2$ (Fig. 4c), and the $\beta$-phase was not found in the micrographs (Fig. 4d).
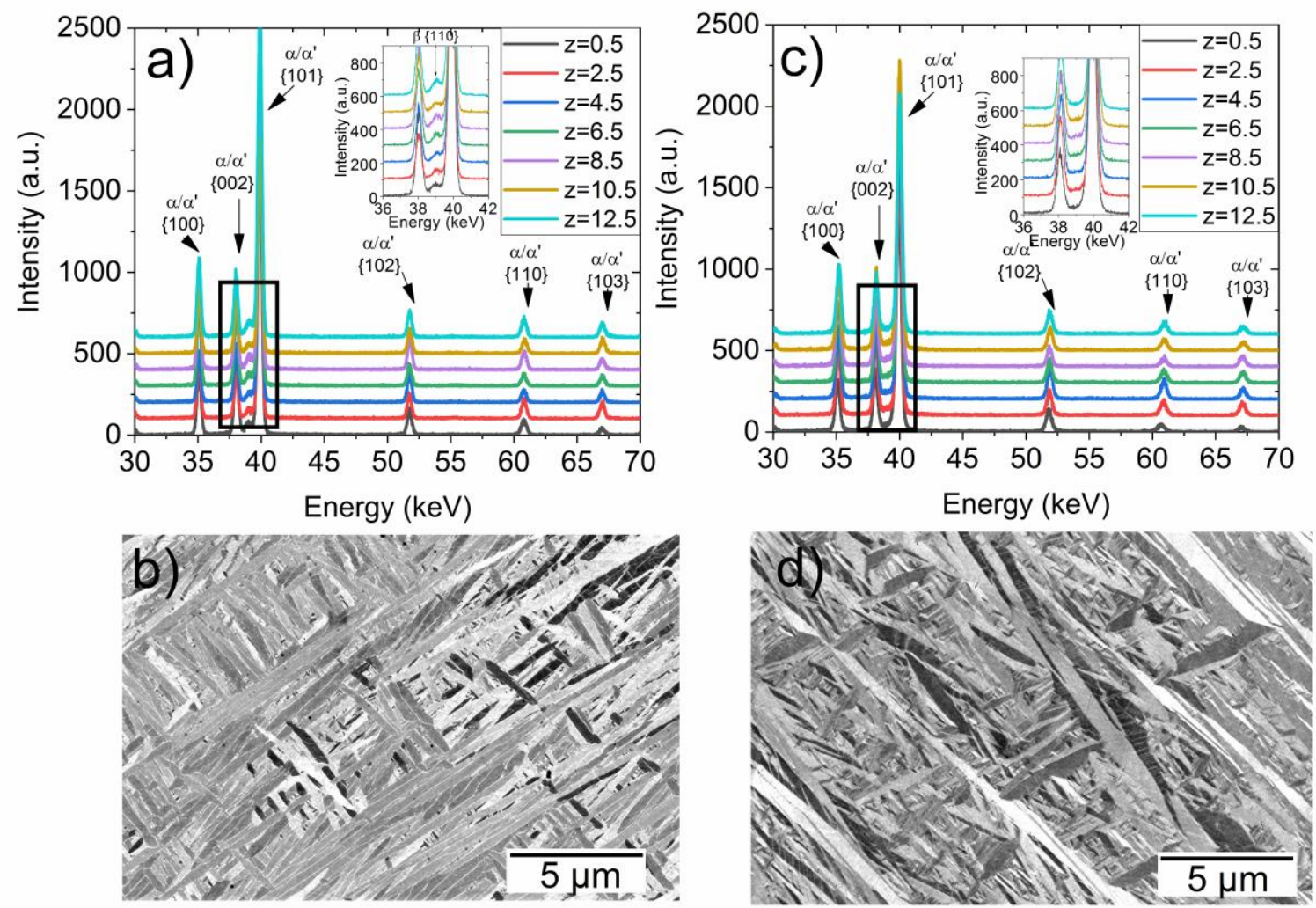

Fig. 3. a) Diffractogram and b) BSE-SEM image taken at the center of the sample of A1H40 sample, c) Diffractogram and d) BSE-SEM image taken at the center of the sample of A4 sample. 


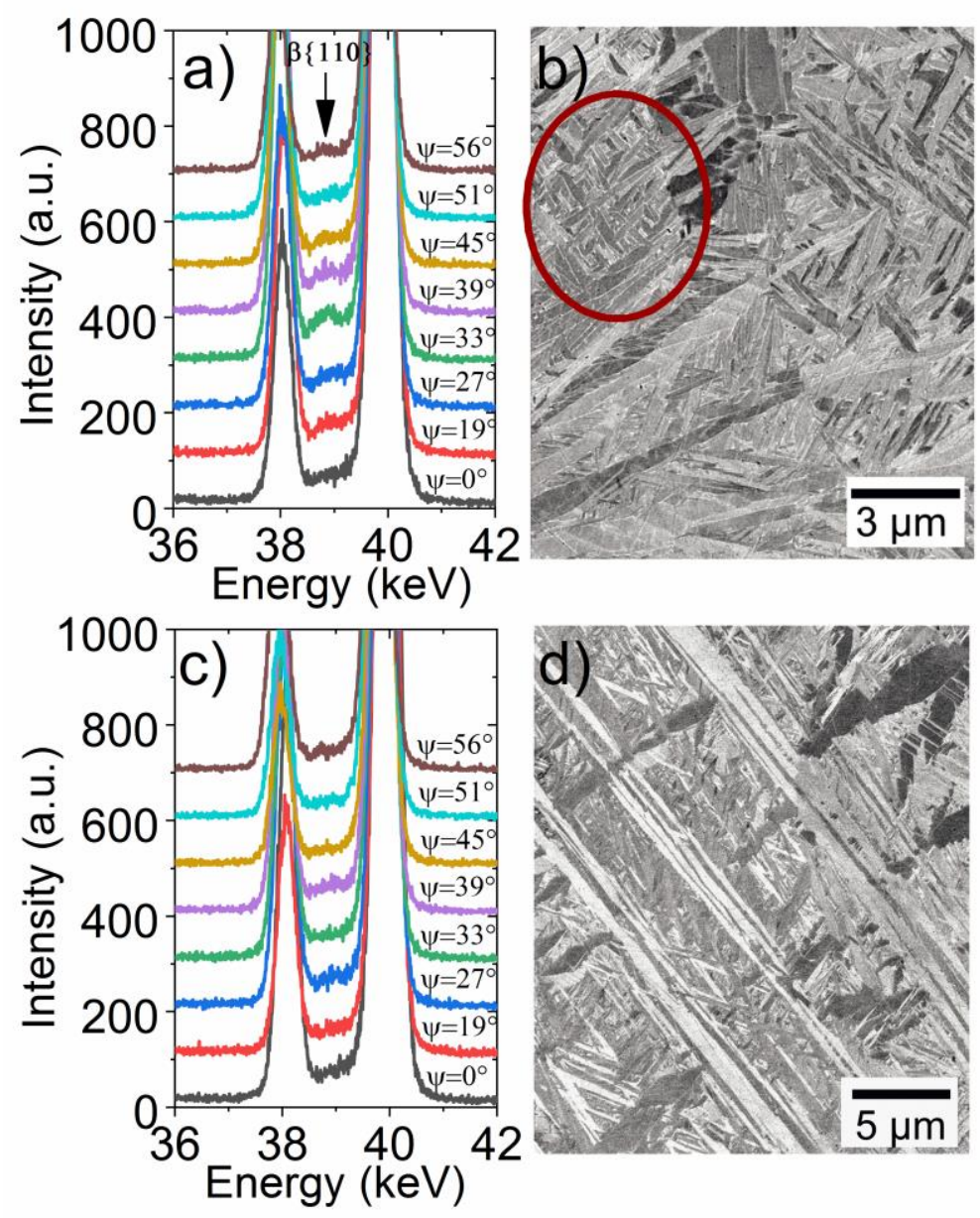

Fig. 4. XRD pattern obtained near the top surface $(Z=2.5 \mathrm{~mm})$ for different $\psi$ angles and BSE-SEM images taken near the top surface: (a), (b) A4F-2 (focus above the powder bed) and (c), (d) A4F+2 (focus below the powder bed).

\subsection{Residual Stress Analysis}

The subsurface RS analysis was performed exclusively for the hexagonal $\left(\alpha+\alpha^{\prime}\right)$-Ti phase, present in all samples. The RS profiles along the height of all samples are shown in Fig. 5. Samples produced at $E_{V}=117 \mathrm{~J} / \mathrm{mm}^{3}$ consistently possess high tensile RS, exceeding 450 MPa (Fig. 5a), whereas samples with high $E_{V}\left(292 \mathrm{~J} / \mathrm{mm}^{3}\right)$ possess stresses below $150 \mathrm{MPa}$ (Fig. 5b). This difference between low and high $E_{V}$ conditions is a consequence the abovementioned IHT. Lower subsurface RS at higher $E_{V}$ were also found in one of our previous studies [21]. All samples show the lowest RS at the top, followed by a sharp increase as a function of depth, and stabilisation above $Z=4 \mathrm{~mm}$. The stress release at the top simply satisfies boundary conditions $\left(\sigma_{z}=0\right.$ at $\left.Z=0\right)$.

The samples with lower $E_{V}\left(117 \mathrm{~J} / \mathrm{mm}^{3}\right)$ show RS variations between $400 \mathrm{MPa}$ and $800 \mathrm{MPa}$ at height $>2 \mathrm{~mm}$ (see Fig. 5a). Most interestingly, the RS profiles observed with the focus 
changes $\mathrm{A} 4 \mathrm{~F}+2$ and $\mathrm{A} 4 \mathrm{~F}-2$ show the highest and lowest values, respectively, thereby forming an envelope for all other conditions. The "optimized" parameter set A4 results in a RS profile lying halfway between A4F+2 and A4F-2. Notably, A4VP70 leads to a subsurface RS level slightly increased by $\sim 50 \mathrm{MPa}$ as compared to the A4 reference. The conditions A4VP280 and $\mathrm{A} 4 \mathrm{~F}+2$ seem to show a RS increase as a function of the distance from the top, in contrast to the other parameter sets, which stabilized to a plateau within $2-3 \mathrm{~mm}$ from the top surface.
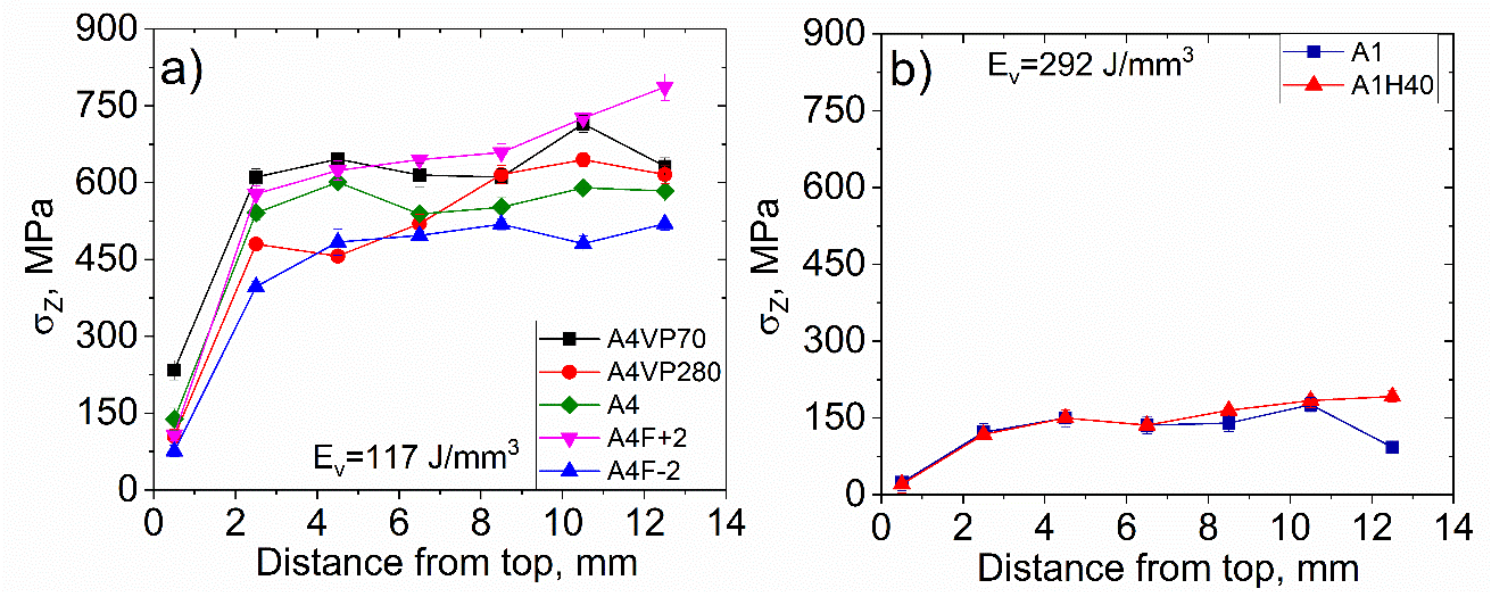

Fig. 5. RS along the building direction for samples produced with a) $E_{V}=117 \mathrm{~J} / \mathrm{mm}^{3}$;

b) $E_{V}=292 \mathrm{~J} / \mathrm{mm}^{3}$.

\subsection{Computed Tomography: analysis of porosity}

CT reconstructions show that the total porosity was below $1 \%$ for all conditions studied, with A4 even below $0.1 \%$ (Table 2). The use of a laser focus above the powder bed (A4F-2) lead to a significant porosity increase to $0.1 \%$. The combined variation of laser power and velocity evidences only a slight increase with respect to the porosity in the optimized parameter set A4. In contrast, the density of samples produced with high $E_{V}$ underwent large variations: While using a reduced hatch distance (A1H40) only weakly affected the porosity, a lower velocity (A1) resulted in a $\sim 50 \times$ increase in porosity.

The contour regions often show accumulation of voids. In some cases pores were mainly located at the transition zone between contour and bulk scans (i.e. at the so-called fill-contour region, located around 500-600 $\mu \mathrm{m}$ from the surface). Therefore, the ratio between porosity at fill-contour region and total porosity was also calculated, and is reported in Table 2. Only the conditions A1 and A4VP70 show predominant bulk porosity, while for the rest the fillcontour region contain $>50 \%$ of total porosity. 
Table 2. Porosity parameters, as determined by CT.

\begin{tabular}{c|c|c|c|c}
\hline Sample & Total porosity, $p[\%]$ & $\begin{array}{c}\text { Bulk } \\
\text { porosity }[\%]\end{array}$ & $\begin{array}{c}\text { Ratio between fill- } \\
\text { contour region and } \\
\text { total porosity }\end{array}$ & $\begin{array}{c}\text { Energy density, } \\
E_{v}\left[\mathrm{~J} / \mathrm{mm}^{3}\right]\end{array}$ \\
\hline $\boldsymbol{A 1}$ & $0.95 \pm 0.04$ & 0.69 & 0.27 & 292 \\
\hline $\boldsymbol{A 1 H 4 0}$ & $0.04 \pm 0.005$ & 0.013 & 0.68 & \\
\hline $\boldsymbol{A 4}$ & $0.008 \pm 0.0005$ & 0.003 & 0.63 & 117 \\
$\boldsymbol{A 4 V P 7 0}$ & $0.02 \pm 0.002$ & 0.018 & 0.10 & \\
$\boldsymbol{A 4 V P 2 8 0}$ & $0.045 \pm 0.002$ & 0.02 & 0.55 & \\
$\boldsymbol{A 4 F - 2}$ & $0.1 \pm 0.03$ & 0.04 & 0.60 & \\
$\boldsymbol{A 4 F + 2}$ & $0.002 \pm 0.0005$ & 0.001 & 0.50 & \\
\hline
\end{tabular}

Elongated, crack like pores, and void accumulation at the borders of samples and components are, from a mechanical point of view, more critical than bulk porosity [35]. The 2D projections along the build direction, i.e. onto XY plane (see Fig. 1), of the 3D CT reconstructed volumes are shown in Fig. 6 and 7. Those figures show the spatial distribution of porosity integrated along an axis perpendicular to the build direction.

The $3 \mathrm{D}$ aspect ratio, $\mathrm{F}_{3 \mathrm{D}}$, was determined by the ratio between the longest $\left(\mathrm{F}_{\max }\right)$ and the shortest Feret diameter $\left(\mathrm{F}_{\min }\right)$ of each void. $\mathrm{F}_{3 \mathrm{D}}=1$ indicates an ideally spherical pore. The shape distributions of all samples are shown in Figs. 6f and 7c.

The comparison between samples manufactured with different laser focus distances shows that this parameter has a large effect on pore size and morphology (Fig. 6a,b,c). The A4F-2 parameter set, while leading to the highest amount of total porosity $(0.1 \%)$, resulted in rounder pores compared to $\mathrm{A} 4 \mathrm{~F}+2$ and $\mathrm{A} 4$. At the same time, in the $\mathrm{A} 4 \mathrm{~F}+2$ and $\mathrm{A} 4$ samples some elongated and irregularly shaped pores could be observed. The most elongated and complex-shaped pores, with aspect ratio up to 11, occurred in A4 (focus $=0$ ) and A4VP70, while A4VP280 resulted in nearly spherical pores $\left(\mathrm{F}_{3 \mathrm{D}}<4\right)$, almost exclusively located in the contour region. Similarly, the samples manufactured with the SLM parameter sets A1 and A1H40 show basically only near spherical pores (Fig.7). 


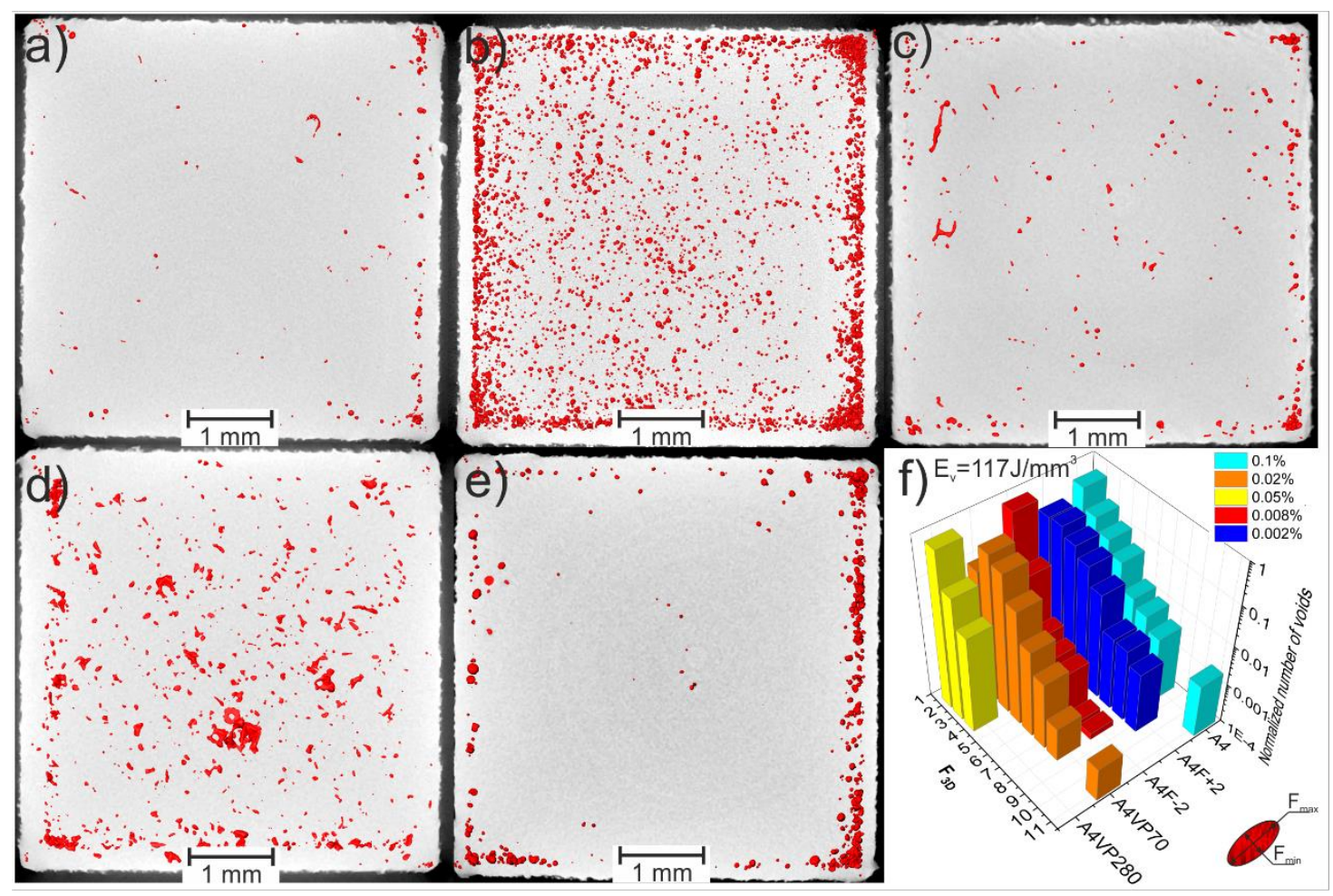

Fig. 6. The global 3D porosity rendering projected onto a 2D slice (XY plane) a) A4F+2, b) A4F-2, c) A4, d) A4VP70, e) A4VP280; The frequency distribution of the ratio between maximum and minimum pore Feret's diameters, $F_{3 D}$, is shown in $f$ ).

Significant porosity differences between the two samples with lower $E_{v}$ (A1 and A1H40) (Fig. 7 a,b) can be clearly observed: In A1H40 most of the pores are concentrated in the region between contour and bulk, whereas only a few pores are found in the bulk. 


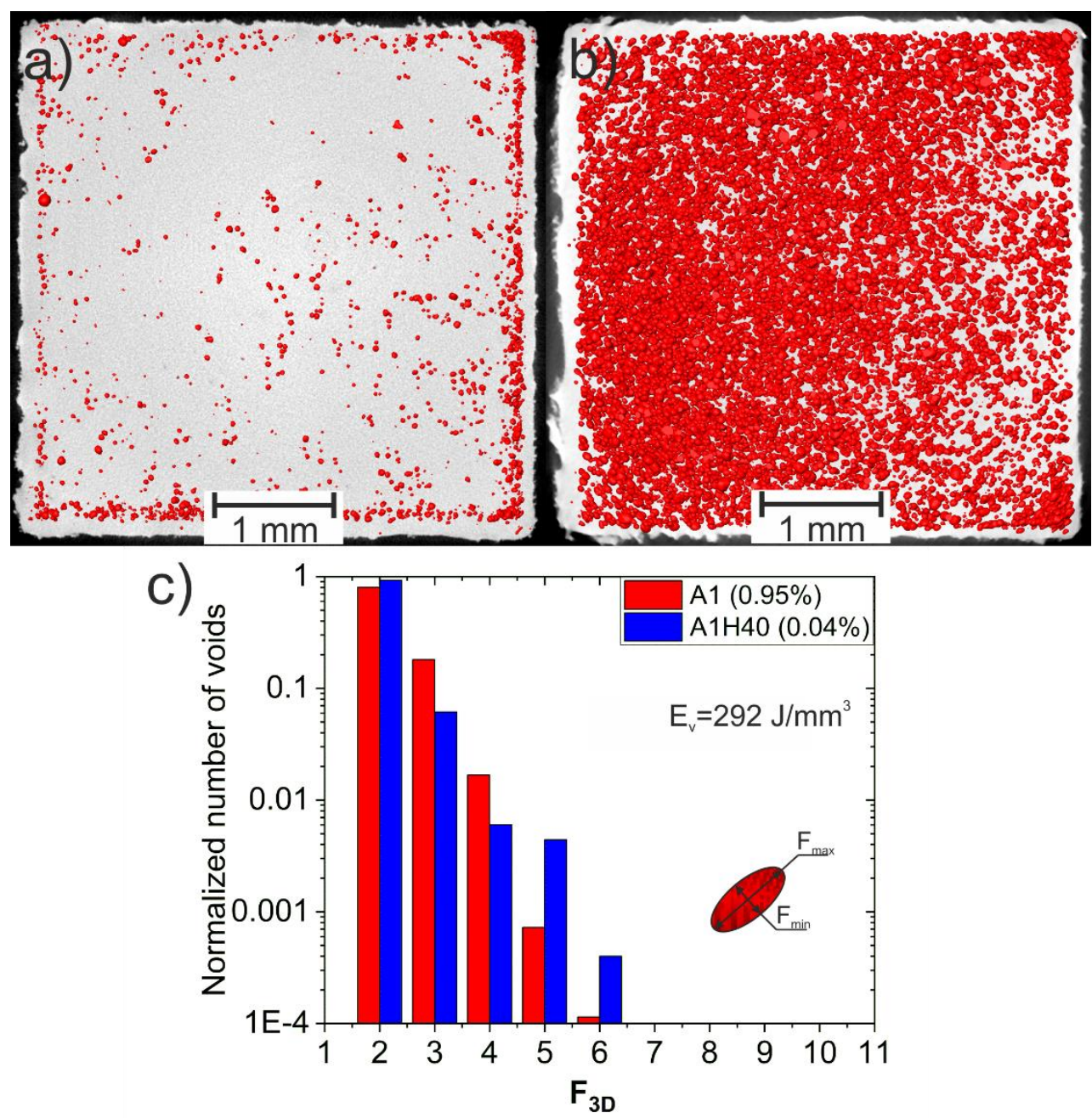

Fig. 7. The 3D porosity rendering from the whole sample projected along the build direction a) $\mathrm{A} 1 \mathrm{H} 40, \mathrm{~b}) \mathrm{A} 1$, c) $\mathrm{F}_{3 \mathrm{D}}$ distribution histogram for the samples with high $E_{v}$.

Fig. 8 shows the 3D aspect ratio $F_{3 D}$ as a function of sphericity, $\Psi$ (Equation 3), for bulk porosity, i.e. neglecting the fill-contour region. The bulk porosity is given in brackets for each condition. A4VP280 (porosity $=0.002 \%$ ) presents the largest fraction of "round" pores (minimum sphericity around 0.85 ). That means that the presence of irregularly-shaped pores (i.e. lack of fusion) could be reduced by increasing laser power and velocity, while keeping the same energy density. Also, the focusing of the laser beam above the powder bed (A4F-2) decreases the number of critical pores (those with low sphericity), while focusing in opposite direction (i.e., below the powder bed, $\mathrm{A} 4 \mathrm{~F}+2$ ) keeps the amount of critical pores similar to the case with focus on the powder bed, i.e. A4 (Fig.8a).

It is to be mentioned that because of the limited resolution of laboratory $\mathrm{CT}$, no information could be extracted about the origin of the pores. This study was beyond the scope of this 
work, and has been partially done in previous work [4, 36] (using Synchrotron Radiation CT and X-ray refraction), to which the reader is referred to for more details.
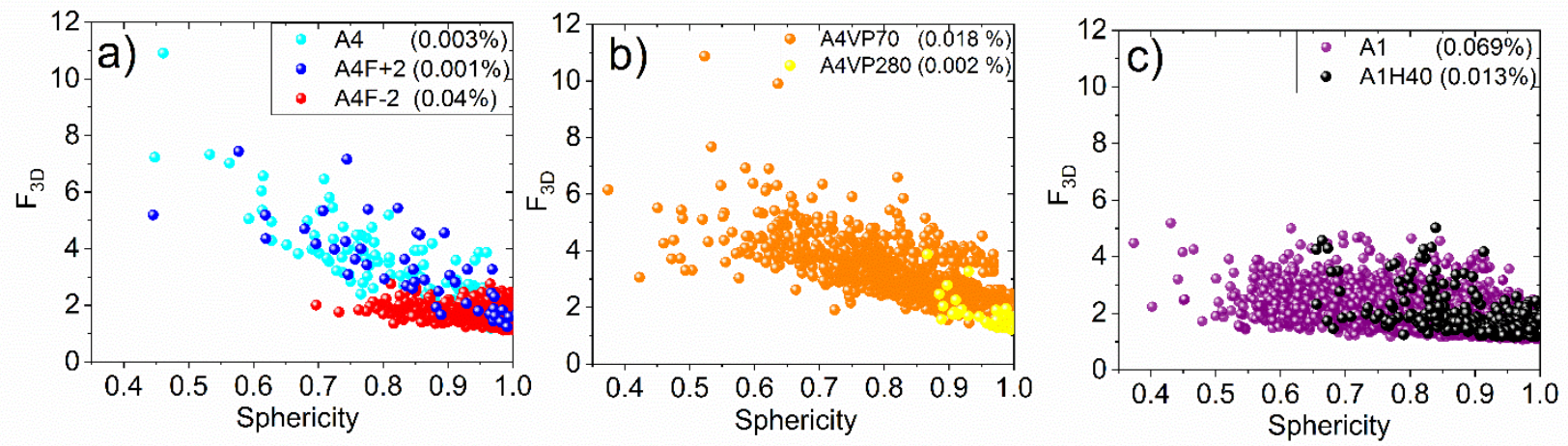

Fig. 8. 3D aspect ratio of pores $\left(\mathrm{F}_{3 \mathrm{D}}\right) v s$. sphericity of bulk porosity for samples a) $\mathrm{A} 4, \mathrm{AF}+2$,

A4F-2; b) A4VP70, A4VP280; c) A1H40, A1. Note: the volume fraction of bulk pores is given in brackets.

\section{Discussion}

We have observed that higher energy input $\left(E_{V}=292 \mathrm{~J} / \mathrm{mm}^{3}\right)$ evidently reduces RS, due to the IHT effect during manufacturing (compare Figs. 5a and 5b). Moreover, the formation of the $\beta$-phase is connected to both the higher energy density and to the short scanning time per layer, via the IHT effect. This is evidenced by the conditions A1 and A1H40, where $\beta$ can be readily observed both by XRD and SEM. This implies that, additional to the IHT effect, the increase in ductility, usually induced by the presence of $\beta$ in SLM Ti6Al4V [11], may also favor relaxation of RS via plastic deformation.

Changes in spatial distribution of voids between contour and bulk region can be observed almost for all samples. The voids in the fill-contour region represent more than $50 \%$ of the porosity for most of the studied conditions (Table 2), except A1 and A4VP70. Therefore, contour parameters ought to be optimized in order to decrease the porosity near the surface (which even is most detrimental for crack initiation). While the decrease of hatch distance results in less elongated pores, the bulk porosity remains low (compare A4 and A1H40 in Table 2 as well as Figs. 6c and 7a). Finite element calculations have also shown that the effect of hatch distance is insignificant in terms of melt pool dimensions [37]. Actually, porosity is more sensitive to the change of laser velocity $(0.008 \%$ for $v=500 \mathrm{~mm} / \mathrm{s} v$ s. $0.95 \%$ for $v=200$ $\mathrm{mm} / \mathrm{s}$ ) than to hatch distance, as also reported in [1]. Indeed, the simple $P / v$ ratio correlates to the porosity level better than $E_{V}$ (see Tab.1). Defects generated by higher energy input usually form due to over-melting, leading to vaporization within the melt pool [3]. All samples with lower $E_{V}$ have bulk porosity $<0.5 \%$ although they can show different pore distributions and 
morphology. Interestingly, the simultaneous increase of scanning velocity and power (sample A4VP280) with respect to the optimized parameter set (sample A4) leads to the decrease of elongated pores, i.e. pores with higher sphericity). In contrast, low power and scanning speed (sample A4VP70) provoke the most irregular shapes, probably caused by lack of fusion.

In the case of samples with different laser focus position (i.e. $\mathrm{A} 4 \mathrm{~F}-2$ and $\mathrm{A} 4 \mathrm{~F}+2$ ), we observe a correspondence between low RS and high porosity. However, in the case of A4F-2, the porosity is around $0.1 \%$ in the contour region (up to $200 \mu \mathrm{m}$ below the surface) and around $0.2 \%$ in the fill-contour region (between 200 and $600 \mu \mathrm{m}$ below the surface). These (low) porosity fractions cannot have any influence on the reduction of subsurface RS. In fact, the dependence of the elastic modulus $E$ on porosity $p$ predicted by micromechanical models [3840] can be summarized in the relation

$$
E=E_{0}(1-p)^{m}
$$

where $E_{0}$ is the elastic modulus of the fully dense material and $m$ a shape factor. The latter is about 2 for spherical pores and increases to over 4 for elongated pores. Therefore, even taking into account the influence of pores with low sphericity (large $m$ ), the decrease of elastic modulus in the case of small porosity would be negligible, and both stress and strain would be undistinguishable from the case of a fully dense sample. Moreover, since plasticity, and thereby capability of relaxing residual stress without damage, is governed by dislocation motion, there is no influence of a small amount of porosity distributed in relatively large pores (size above 15-20 $\mu \mathrm{m}$ ). We can therefore exclude any stress relaxation due to porosity.

Of all the samples that were manufactured with low energy density, those manufactured with a de-focused laser beam (A4F-2 and $\mathrm{A} 4 \mathrm{~F}+2)$ possess the smallest and the largest RS values, respectively. The stress difference varies between 200 and $350 \mathrm{MPa}$ along the sample height. Moreover, the sample manufactured with the very same parameters but with a focused laser (A4) presents intermediate RS levels between the two limiting values. This observation can be explained with the different volumetric energy input (Fig. 9): certainly, sample A4F-2 experienced higher temperatures than $\mathrm{A} 4 \mathrm{~F}+2$ during production, which allowed a partial IHT. This led to a larger amount of $\beta$-phase at some locations (Fig. 4). Such a change in the microstructure by shifting the laser focus has also been reported for SLM IN718 [41]. Possibly, the presence of a larger amount of $\beta$ for A4F-2 could favor RS relaxation.

Several reasons, which go back to the complex physics of the laser-material interactions in laser powder bed fusion, may contribute to the changes caused by a focus shift. Usually, 
during laser scanning metal vapor and plasma (overheated, ionized gases) form [42-44]. Material, metal vapor, and heated process gas may be ejected in a "process plume" that can extend up to several millimeters height; these effects change substantially with the chosen laser scan speed and power [44]. The process plume and plasma lead to changes of the refractive index, thus affecting the laser by de-focusing and deflecting its path [44]. Changes in the laser interaction with the process plume and with the plasma may directly translate into changes in the heat transfer during the SLM process [44]. In order to elucidate these effects in detail, systematic studies would be needed, which, however, lay outside the scope and realm of the current study.

Another contribution to this observation may arise from the sample positioning on the baseplate during manufacturing. To systematically investigate this possibility, a RS analysis was performed on four samples. They were labeled N1, N7 (i.e., sample A4 reported above, see Fig.5), N12, and N18, and all manufactured with identical parameters to A4 (Fig. 10a). A further sample, named N1', with same process parameters, but extracted from a different build job and placed in the same position as N1, was investigated to check build-to-build variations. For full comparability, the two build jobs were set up with the same scanning time per layer and interlayer dwell time. The same lateral surfaces, marked by yellow lines in Fig. 10a, were analyzed for all samples.

The RS profiles along the sample height (Fig. 10b) showed a similar behavior for all samples (and similar to those reported in Fig. 5a), with a maximum RS difference of about $200 \mathrm{MPa}$ and a typical interval width of $150 \mathrm{MPa}$. Samples at the bottom two rows (N12 and N18, nearest to the Argon inlet into the build chamber) showed similar stress values (except for one single point), and lower stresses than samples in the top row (N1). Interestingly, sample N7 (close to center of the base plate) displayed stress values that lie in-between. Finally, the very same stress values were observed in $\mathrm{N} 1$ and N1', thereby confirming reproducibility of successive build jobs. 

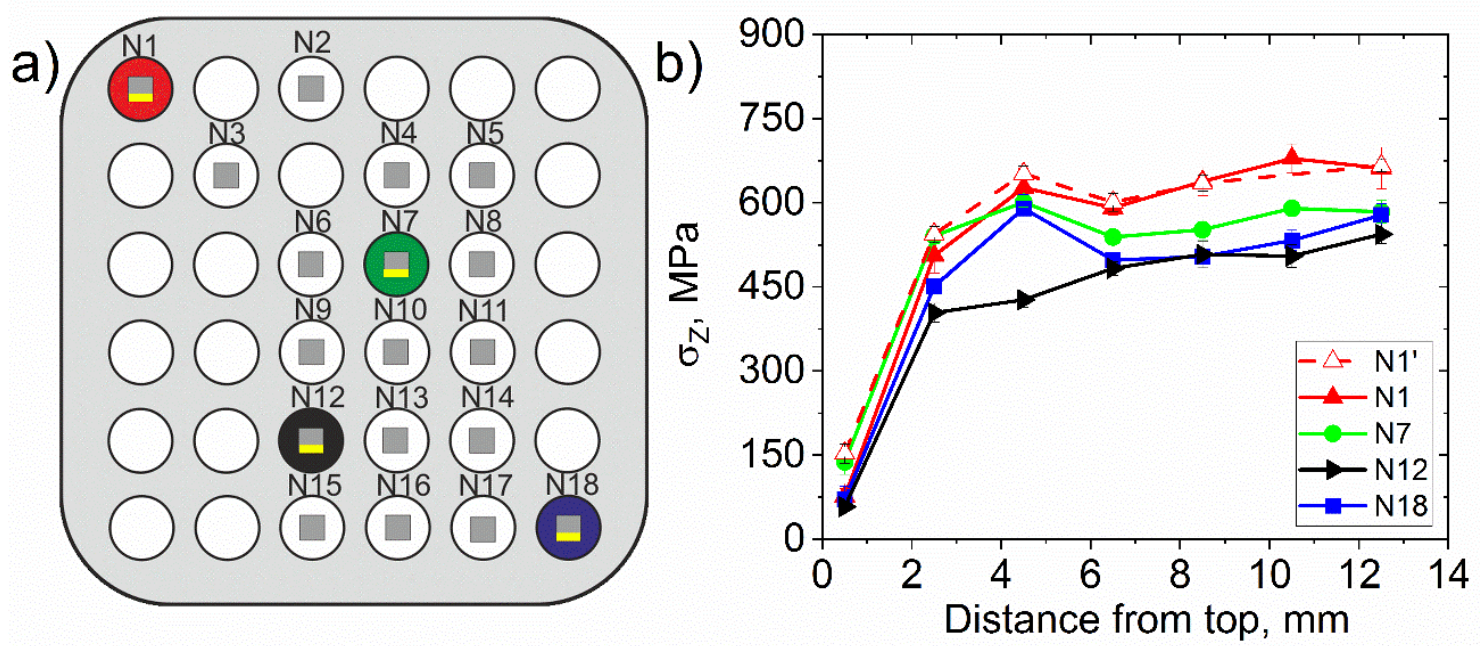

Fig. 10. a) Sketch of the base plate $\left(\right.$ size $280 \times 280 \mathrm{~mm}^{2}$ ) with sample nomenclature (yellow lines specify the analyzed surfaces); b) RS profiles for the samples at different positions on the base plate.

The positions of samples A4F-2, A4F+2, and A4 corresponded to N11, N7, and N5, respectively (Fig. 10a). We see that while the different sample position (N5 to N11) would certainly induce some stress difference between $\mathrm{A} 4 \mathrm{~F}-2$ and $\mathrm{A} 4 \mathrm{~F}+2$, this difference could never be as large as the measured one (200-350 MPa), simply because the maximum stress difference due to sample position (i.e. throughout the whole chamber) lies around 150-200 MPa (Fig. 10b). The measured effects of laser de-focusing on RS is therefore genuinely dictated by energy distribution considerations during the solidification process.

However, the data reported in Fig. 10b undoubtedly show that the position on the base plate needs to be treated as an additional parameter for the optimization of SLM components. One factor causing the observed RS variation as a function of the sample position on the base plate may be the laser path. The laser gun is initially placed in the center of the base plate; this may be the reason why samples N1 and N12/N18 at two opposite sides of the base plate show the maximum RS difference (Fig. 10b). In the case of the N1 sample, the surface used for RS analysis was oriented in such a way that the laser was directed towards material that had already solidified (Fig. 11a, red path). In this case, heat dissipation could occur rapidly (larger thermal conductivity). In the case of N12 and N18 the surface used for RS analysis saw the laser going towards the powder (Fig. 11a, blue path), which has a lower thermal conductivity. In this case, heat dissipation could not occur as rapidly as in the case of N1 and, therefore, the sample remained warmer for longer time. This allowed partial relaxation of the residual stresses. Another factor that may significantly influence the RS variation as function of 
sample position on the base plate is the inhomogeneous Argon flow (schematically shown in Fig. 11b). The impact of an inhomogeneous gas flow on porosity and compressive strength has been also reported in [45]. A systematic study of this effect would be required, but it lies beyond the scope of this work, and it is left for future investigations.

a)

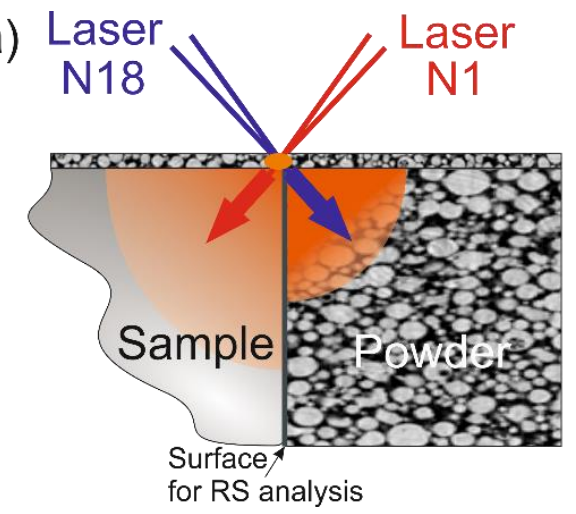

b)

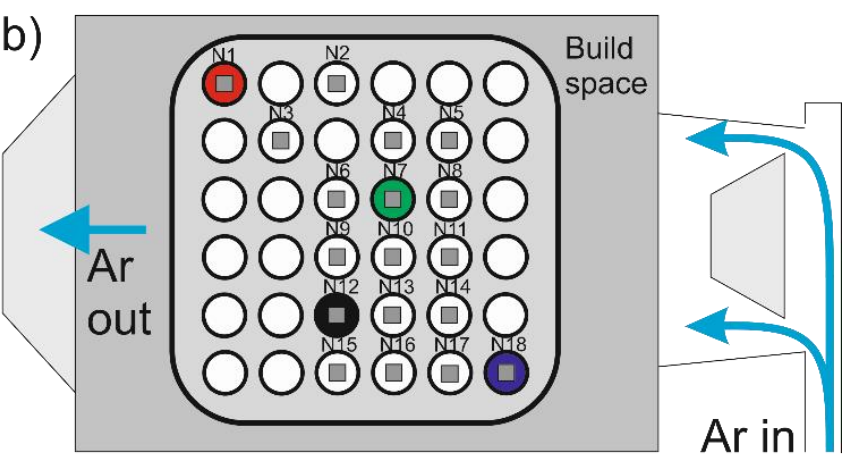

Fig. 11. a) Schematic representation of laser scanning principle for samples with different position on the base plate N18 and N1; b) schematic representation of Argon flow.

In conclusion, while the ability to manufacture SLM samples with reproducible properties (e.g. tensile strength), keeping the same process parameters and powder quality, has been proven [46], we point out new important aspects that need full consideration while producing components or test specimens in series. Factors such as the position inside the build chamber or the homogeneity of gas flow need to be investigated in a more systematic manner, and possibly other parameters in the build job need also to be taken into account. Quoting Albert Einstein: "We should make things as simple as possible, but not simpler".

\section{Summary and Conclusions}

Subsurface residual stresses (RS) were studied in several SLM Ti-6Al-4V prisms. These were manufactured by varying the process parameters around an optimal parameter set (i.e. keeping the energy $E_{V}$ constant at the optimum value). Additionally, we compared two energy densities. In parallel, defects (porosity and spatial distribution of pores) were investigated by $\mathrm{x}$-ray computed tomography.

We were able to identify the most relevant process parameters heavily influencing RS in SLM Ti-6Al-4V, within a reference process window previously optimized in terms of porosity, and to add new factors: 
- Upon reduction of the hatch distance from the standard $100 \mu \mathrm{m}$ down to $40 \mu \mathrm{m}$ one can stabilize the microstructure without affecting porosity, and simultaneously reducing sub-surface residual stress from about $600 \mathrm{MPa}$ to about $150 \mathrm{MPa}$. This, however, also requires very short layer scan times.

- For the same energy density, one can obtain different pore shapes depending on heat input. In fact, one can minimize the presence of crack-like pores by increasing laser power and speed with respect to the reference, optimized condition. The presence of keyhole pores might be further reduced by increasing laser speed above $800 \mathrm{~mm} / \mathrm{s}$ (at $\mathrm{P}=280 \mathrm{~W}$, hatch distance $=100 \mu \mathrm{m})$.

- We demonstrated that porosity has negligible influence on subsurface RS and its relaxation, possibly because of its low values $(<1 \%)$, even if pores are mainly concentrated in the fill-contour regions.

- Sample position on the base plate showed to have an influence on the RS state. This was qualitatively explained by the different heat dissipation mechanisms occurring on lose powder and in bulk metal. Possibly, this effect is exacerbated by the uneven Argon flow inside the chamber.

- Laser focus distance has an influence on the RS state, i.e. focusing the laser below the powder bed yield smaller RS. In the case of focusing above the powder bed, a larger temperature is reached, proven by the presence of $\beta$, which allows RS relaxation. While the effect of de-focusing is convoluted with the effect of sample position in the chamber, we could show that the first is quantitatively dominant over the second.

We concluded that more systematic investigations are still needed to better quantify the factors we investigated in this work, and explore the effect of other factors not contained herein. Furthermore, by demonstrating that optimizing porosity and pore shapes does not minimize RS, we recommend defining the property to be optimized before using 'optimum' process parameter sets.

\section{Acknowledgements}

T. Merzouk and A. Turak are acknowledged for the manufacturing of the SLM samples at DLR. Authors thank M. Klaus and Ch. Genzel (Helmholz Zentrum Berlin) for the support during beamtime. 


\section{References}

[1] B. Dutta, F.H. Froes, Chapter 1 - The Additive Manufacturing of Titanium Alloys, in: B. Dutta, F.H. Froes (Eds.), Additive Manufacturing of Titanium Alloys, ButterworthHeinemann2016, pp. 1-10.

[2] A.A. Antonysamy, J. Meyer, P.B. Prangnell, Effect of build geometry on the $\beta$-grain structure and texture in additive manufacture of Ti6Al4V by selective electron beam melting, Materials Characterization 84 (2013) 153-168.

[3] H. Gong, K. Rafi, H. Gu, T. Starr, B. Stucker, Analysis of defect generation in Ti-6Al-4V parts made using powder bed fusion additive manufacturing processes, Additive Manufacturing 1-4 (2014) 87-98.

[4] G. Kasperovich, J. Haubrich, J. Gussone, G. Requena, Correlation between porosity and processing parameters in TiAl6V4 produced by selective laser melting, Materials \& Design 105 (2016) 160-170.

[5] S. Tammas-Williams, P.J. Withers, I. Todd, P.B. Prangnell, The Influence of Porosity on Fatigue Crack Initiation in Additively Manufactured Titanium Components, Sci Rep 7(1) (2017) 7308.

[6] A. Thompson, I. Maskery, R.K. Leach, X-ray computed tomography for additive manufacturing: a review, Measurement Science and Technology 27(7) (2016).

[7] S. Tammas-Williams, H. Zhao, F. Léonard, F. Derguti, I. Todd, P.B. Prangnell, XCT analysis of the influence of melt strategies on defect population in $\mathrm{Ti}-6 \mathrm{Al}-4 \mathrm{~V}$ components manufactured by Selective Electron Beam Melting, Materials Characterization 102 (2015) 4761.

[8] S. Khademzadeh, S. Carmignato, N. Parvin, F. Zanini, P.F. Bariani, Micro porosity analysis in additive manufactured NiTi parts using micro computed tomography and electron microscopy, Materials \& Design 90 (2016) 745-752.

[9] K.G. Prashanth, S. Scudino, T. Maity, J. Das, J. Eckert, Is the energy density a reliable parameter for materials synthesis by selective laser melting?, Materials Research Letters 5(6) (2017) 386-390.

[10] U. Scipioni Bertoli, A.J. Wolfer, M.J. Matthews, J.-P.R. Delplanque, J.M. Schoenung, On the limitations of Volumetric Energy Density as a design parameter for Selective Laser Melting, Materials \& Design 113 (2017) 331-340.

[11] W. Xu, M. Brandt, S. Sun, J. Elambasseril, Q. Liu, K. Latham, K. Xia, M. Qian, Additive manufacturing of strong and ductile $\mathrm{Ti}-6 \mathrm{Al}-4 \mathrm{~V}$ by selective laser melting via in situ martensite decomposition, Acta Materialia 85 (2015) 74-84.

[12] S.Q. Wu, Y.J. Lu, Y.L. Gan, T.T. Huang, C.Q. Zhao, J.J. Lin, S. Guo, J.X. Lin, Microstructural evolution and microhardness of a selective-laser-melted $\mathrm{Ti}-6 \mathrm{Al}-4 \mathrm{~V}$ alloy after post heat treatments, Journal of Alloys and Compounds 672 (2016) 643-652.

[13] P. Barriobero-Vila, J. Gussone, J. Haubrich, S. Sandlöbes, J. Da Silva, P. Cloetens, N. Schell, G. Requena, Inducing Stable $\alpha+\beta$ Microstructures during Selective Laser Melting of Ti-6Al-4V Using Intensified Intrinsic Heat Treatments, Materials 10(3) (2017) 268.

[14] L. Thijs, F. Verhaeghe, T. Craeghs, J.V. Humbeeck, J.-P. Kruth, A study of the microstructural evolution during selective laser melting of Ti-6Al-4V, Acta Materialia 58(9) (2010) 3303-3312.

[15] W. Xu, E.W. Lui, A. Pateras, M. Qian, M. Brandt, In situ tailoring microstructure in additively manufactured Ti-6Al-4V for superior mechanical performance, Acta Materialia 125 (2017) 390-400.

[16] P. Mercelis, J.P. Kruth, Residual stresses in selective laser sintering and selective laser melting, Rapid Prototyping Journal 12(5) (2006) 254-265. 
[17] I. Yadroitsev, I. Yadroitsava, Evaluation of residual stress in stainless steel 316L and Ti6Al4V samples produced by selective laser melting, Virtual and Physical Prototyping 10(2) (2015) 67-76.

[18] C. Pappalettere, S.L. Campanelli, C. Casavola, Preliminary investigation on distribution of residual stress generated by the selective laser melting process, The Journal of Strain Analysis for Engineering Design 44(1) (2009) 93-104.

[19] J.P. Kruth, J. Deckers, E. Yasa, R. Wauthle, Assessing and comparing influencing factors of residual stresses in selective laser melting using a novel analysis method, Proceedings of the Institution of Mechanical Engineers, Part B: Journal of Engineering Manufacture 226(6) (2012) 980-991.

[20] Z. Chen, X. Wu, D. Tomus, C.H.J. Davies, Surface roughness of Selective Laser Melted Ti-6Al-4V alloy components, Additive Manufacturing 21 (2018) 91-103.

[21] T. Mishurova, S. Cabeza, K. Artzt, J. Haubrich, M. Klaus, C. Genzel, G. Requena, G. Bruno, An Assessment of Subsurface Residual Stress Analysis in SLM Ti-6Al-4V, Materials 10(4) (2017) 348-362.

[22] C. Genzel, I.A. Denks, J. Gibmeier, M. Klaus, G. Wagener, The materials science synchrotron beamline EDDI for energy-dispersive diffraction analysis, Nuclear Instruments and Methods in Physics Research Section A: Accelerators, Spectrometers, Detectors and Associated Equipment 578(1) (2007) 23-33.

[23] N. Nadammal, A. Kromm, R. Saliwan-Neumann, L. Farahbod, C. Haberland, P.D. Portella, Influence of Support Configurations on the Characteristics of Selective Laser-Melted Inconel 718, Jom 70(3) (2017) 343-348.

[24] T. Simson, A. Emmel, A. Dwars, J. Böhm, Residual stress measurements on AISI 316L samples manufactured by selective laser melting, Additive Manufacturing 17 (2017) 183-189. [25] B. Ahmad, S.O. van der Veen, M.E. Fitzpatrick, H. Guo, Residual stress evaluation in selective-laser-melting additively manufactured titanium (Ti-6Al-4V) and inconel 718 using the contour method and numerical simulation, Additive Manufacturing 22 (2018) 571-582.

[26] B. Cheng, S. Shrestha, K. Chou, Stress and deformation evaluations of scanning strategy effect in selective laser melting, Additive Manufacturing 12 (2016) 240-251.

[27] V. Hauk, Structural and Residual Stress Analysis by Nondestructive Methods A2 Structural and Residual Stress Analysis by Nondestructive Methods, Elsevier Science B.V., Amsterdam, 1997.

[28] G. Kasperovich, J. Hausmann, Improvement of fatigue resistance and ductility of TiAl6V4 processed by selective laser melting, Journal of Materials Processing Technology 220 (2015) 202-214.

[29] H. Dölle, The Influence of Multiaxial Stress States, Stress Gradients and Elastic Anisotropy on the Evalution of (Residual) Stress by X-rays, Journal of Applied Crystallography 12(489-501) (1979).

[30] E. Kröner, Berechnung der elastischen Konstanten des Vielkristalls aus den Konstanten des Einkristalls, Zeitschrift für Physik 151(4) (1958) 504-518.

[31] J.D. Eshelby, The Determination of the Elastic Field of an Ellipsoidal Inclusion, and Related Problems, Proceedings of the Royal Society of London. Series A. Mathematical and Physical Sciences 241(1226) (1957) 376-396.

[32] E.C. Oliver, M.R. Daymond, J. Quinta da Fonseca, P.J. Withers, Intergranular Stress Evolution in Titanium Studied by Neutron Diffraction and Self-consistent Modelling, Journal of Neutron Research 12(1-3) (2004) 33-37.

[33] ISO Standard 21432- Non-destructive testing - Standard test method for determining residual stresses by neutron diffraction, 2018.

[34] G.Bruno, B.D.Dunn, Surface and bulk Residual Stress in Ti6Al4V aerospace welded tanks, J.Press.Vess.Tech. 126 (2004) 284-292. 
[35] S. Leuders, M. Thöne, A. Riemer, T. Niendorf, T. Tröster, H.A. Richard, H.J. Maier, On the mechanical behaviour of titanium alloy TiAl6V4 manufactured by selective laser melting: Fatigue resistance and crack growth performance, International Journal of Fatigue 48 (2013) 300-307.

[36] R. Laquai, B.R. Müller, G. Kasperovich, J. Haubrich, G. Requena, G. Bruno, X-ray refraction distinguishes unprocessed powder from empty pores in selective laser melting Ti6Al-4V, Materials Research Letters 6(2) (2018) 130-135.

[37] J.-R. Zhuang, Y.-T. Lee, W.-H. Hsieh, A.-S. Yang, Determination of melt pool dimensions using DOE-FEM and RSM with process window during SLM of Ti6A14V powder, Optics \& Laser Technology 103 (2018) 59-76.

[38] G. Bruno, M. Kachanov, D.J. Green, Microstructure-Property Connections for Porous Ceramics: The Possibilities Offered by Micromechanics, Journal of the American Ceramic Society 99(12) (2016) 3829-3852.

[39] G. Bruno, A.M. Efremov, A.N. Levandovskyi, B. Clausen, Connecting the macro- and microstrain responses in technical porous ceramics: modeling and experimental validations, Journal of Materials Science 46(1) (2010) 161-173.

[40] A. Shyam, G. Bruno, T.R. Watkins, A. Pandey, E. Lara-Curzio, C.M. Parish, R.J. Stafford, The effect of porosity and microcracking on the thermomechanical properties of cordierite, Journal of the European Ceramic Society 35(16) (2015) 4557-4566.

[41] T.D. McLouth, G.E. Bean, D.B. Witkin, S.D. Sitzman, P.M. Adams, D.N. Patel, W. Park, J.-M. Yang, R.J. Zaldivar, The effect of laser focus shift on microstructural variation of Inconel 718 produced by selective laser melting, Materials \& Design 149 (2018) 205-213.

[42] M. Grasso, A.G. Demir, B. Previtali, B.M. Colosimo, In situ monitoring of selective laser melting of zinc powder via infrared imaging of the process plume, Robotics and ComputerIntegrated Manufacturing 49 (2018) 229-239.

[43] W.E. King, H.D. Barth, V.M. Castillo, G.F. Gallegos, J.W. Gibbs, D.E. Hahn, C. Kamath, A.M. Rubenchik, Observation of keyhole-mode laser melting in laser powder-bed fusion additive manufacturing, Journal of Materials Processing Technology 214(12) (2014) 2915-2925.

[44] P. Bidare, I. Bitharas, R.M. Ward, M.M. Attallah, A.J. Moore, Fluid and particle dynamics in laser powder bed fusion, Acta Materialia 142 (2018) 107-120.

[45] B. Ferrar, L. Mullen, E. Jones, R. Stamp, C.J. Sutcliffe, Gas flow effects on selective laser melting (SLM) manufacturing performance, Journal of Materials Processing Technology 212(2) (2012) 355-364.

[46] K. Prashanth, S. Scudino, R. Chatterjee, O. Salman, J. Eckert, Additive Manufacturing: Reproducibility of Metallic Parts, Technologies 5(1) (2017). 